\title{
Development and acceptability testing of ready-to-use supplementary food made from locally available food ingredients in Bangladesh
}

Tahmeed Ahmed ${ }^{1,2^{*}}$, Nuzhat Choudhury ${ }^{1}$ M lqbal Hossain ${ }^{1,2}$, Nattapol Tangsuphoom³, M Munirul Islam', Saskia de Pee ${ }^{4}$, Georg Steiger ${ }^{5}$, Rachel Fuli' ${ }^{6}$, M Shafiqul A Sarker ${ }^{1}$, Monira Parveen ${ }^{6}$, Keith P West Jr. ${ }^{7}$ and Parul Christian ${ }^{7}$

\begin{abstract}
Background: Inadequate energy and micronutrient intake during childhood is a major public health problem in developing countries. Ready-to-use supplementary food (RUSF) made of locally available food ingredients can improve micronutrient status and growth of children. The objective of this study was to develop RUSF using locally available food ingredients and test their acceptability.

Methods: A checklist was prepared of food ingredients available and commonly consumed in Bangladesh that have the potential of being used for preparing RUSF. Linear programming was used to determine possible combinations of ingredients and micronutrient premix. To test the acceptability of the RUSF compared to Pushti packet (a cereal based food-supplement) in terms of amount taken by children, a clinical trial was conducted among 90 children aged 6-18 months in a slum of Dhaka city. The mothers were also asked to rate the color, flavor, mouth-feel, and overall liking of the RUSF by using a 7-point Hedonic Scale ( 1 = dislike extremely, 7 = like extremely).

Results: Two RUSFs were developed, one based on rice-lentil and the other on chickpea. The total energy obtained from $50 \mathrm{~g}$ of rice-lentil, chickpea-based RUSF and Pushti packet were 264, 267 and $188 \mathrm{kcal}$ respectively. Children were offered $50 \mathrm{~g}$ of RUSF and they consumed (mean \pm SD) $23.8 \pm 14 \mathrm{~g}$ rice-lentil RUSF, $28.4 \pm 15 \mathrm{~g}$ chickpea based RUSF. Pushti packet was also offered $50 \mathrm{~g}$ but mothers were allowed to add water, and children consumed $17.1 \pm 14 \mathrm{~g}$. Mean feeding time for two RUSFs and Pushti packet was 20.9 minutes. Although the two RUSFs did not differ in the amount consumed, there was a significant difference in consumption between chickpea-based RUSF and Pushti packet $(p=0.012)$. Using the Hedonic Scale the two RUSFs were more liked by mothers compared to Pushti packet.
\end{abstract}

Conclusions: Recipes of RUSF were developed using locally available food ingredients. The study results suggest that rice-lentil and chickpea-based RUSF are well accepted by children.

Trial registration: ClinicalTrials.gov NCT01553877. Registered 24 January 2012.

Keywords: Ready-to-use supplementary food (RUSF), Local food ingredients, Development, Acceptability

\footnotetext{
*Correspondence: tahmeed@icddrb.org

${ }^{1}$ Centre for Nutrition and Food Security, icddr,b, 68 Shaheed Tajuddin

Ahmed Sarani, Mohakhali, Dhaka 1212, Bangladesh

${ }^{2}$ James P. Grant School of Public Health, BRAC University, Dhaka, Bangladesh

Full list of author information is available at the end of the article
} 


\section{Background}

Bangladesh has one of the highest childhood malnutrition rates in the world. The prevalence of underweight $(<-2 \mathrm{z}$ score weight-for-age) among children less than five years old is 36 percent and stunting $(<-2 \mathrm{z}$ score height-for-age), which denotes chronic malnutrition, is 41 percent [1]. Bangladesh has an estimated 600,000 children with severe acute malnutrition (SAM) and 1.8 million with moderate acute malnutrition (MAM). As a result, currently there are 2.4 million children under five years of age in the country suffering from acute malnutrition ( $<-2 \mathrm{z}$ score weight-for-height) [1]. Malnutrition is nearly always accompanied by deficiencies of essential micronutrients, raising the importance of evaluating the impact of micronutrient content of food products in reducing micronutrient deficiencies during 6-12 months of life [2]. Although breast feeding rates have increased considerably in Bangladesh (90 percent of under-two children breast fed and 64 percent exclusively breast fed during the first 6 months of life), only 24 percent of young children are fed as per appropriate infant and young child feeding (IYCF) practices [1]. Research done in rural Bangladesh showed that complementary foods are grossly deficient in essential micronutrients [3]. In a recent study we assessed the adequacy of intake of 11 micronutrients among 24-48 months children in rural Bangladesh [4]. The overall mean prevalence of adequacy of micronutrient intakes for children was only 43 percent. The prevalence of adequacy was less than 50 percent for iron, calcium, riboflavin, folate, and vitamin B12. In the same population we observed that children consumed sub-optimal amounts of fat and in most children, only one to four percent of the total energy came from essential fatty acids [5]. These observations reflect food insecurity which affects about 20-30 percent of the population of the country, as well as low dietary diversity and low feeding frequency of young children among a larger part of the population. Although effective counseling to improve the quality of complementary feeding works in food secure communities, supplementation with nutritious food may be imperative for children, especially those who cannot afford an adequately diverse diet [6,7].

To reduce growth faltering among young children in resource constrained countries several food supplements have been developed and tested with contrasting results [8-10]. However, considering the country context, a new supplementary food made of locally available food ingredients needs to be developed in Bangladesh. This new supplementary food was designed similar to the Pushti packet (a mixture of roasted rice and lentil flour, with molasses and oil), the food supplement used in the erstwhile National Nutrition Program of Bangladesh. This food supplement is referred in this paper as 'Ready-to-use supplementary food' (RUSF) made of locally available food ingredients and designed to have the required amount of micronutrients and vitamins essential for growth and development of children 6-24 months of age. RUSF does not require cooking and can be consumed without adding water either on its own or by mixing with other food such as rice porridge. It has minimal water content and thus, the risk of contamination or bacterial growth is greatly reduced. These characteristics make provision of RUSF a safe nutrition for young children in Bangladesh. This paper aims to describe the formulation of newly developed RUSF recipes and to assess whether these RUSF are acceptable compared with the existing Pushti packet among children aged 6-18 months in a clinical trial design.

\section{Methods}

\section{Development of RUSF}

\section{Selection of ingredients}

As part of the development of RUSF, a checklist was prepared for all food ingredients available and commonly consumed in Bangladesh that have the potential of being used for developing a RUSF. A final selection was made based on the nutritive value, local availability, and cost of the local ingredients. All ingredients were purchased from the local market. Vitamin and mineral premix was obtained from DSM Switzerland.

\section{Recipe formulation and production}

The theoretical formulation of RUSF components was made based on linear programming to identify the combinations of ingredients that would result in the most nutritious recipes. Linear programming analysis is a powerful approach for identifying a low-cost nutritionally adequate diet [11] which is based on a mathematical iterative approach involving multiple calculations of products and sums that can be quickly performed by a personal computer [12]. The energy density of RUSF was targeted at $250 \mathrm{kcal} / 50 \mathrm{~g}$ (per serving), and caloric distribution was targeted to be $45-50$ percent from fat and 8-10 percent from protein. Based on expert opinion and consensus within the research team, micronutrient content was set to cover 70 percent of the requirements of children aged 6-18 months. Experiments for developing recipes and preparation of samples were done at the icddr,b Food Processing Laboratory following a standardized production procedure to control the quality of RUSF from each production batch and ensure that no unexpected contamination and nutrient losses occur during processing. Potential recipes were produced in small batches by mixing all ingredients in an electric blender. When necessary, consistency of the recipe was adjusted by varying the amount of dry ingredients and soybean oil. Furthermore, the combination of minerals and vitamins were adjusted to avoid unpleasant taste which can occur with addition of high dose of micronutrients. A 
small amount (1 percent) of soy lecithin was added to the recipe in order to improve the consistency and prevent oil separation.

\section{Determination of RUSF quality and stability}

Microbiological tests (total viable count, yeasts, moulds, coliforms, Escherichia coli, Bacillus cereus, Staphylococci, Listeria monocytogenes, Cronobacter sakazaki) were done at icddr,b Food Safety Laboratory. Chemical properties (pH, water activity, moisture, peroxide value, total aflatoxin), nutritional composition (protein, fat, energy, carbohydrates) and micronutrient composition (vitamins, and minerals) were determined at the Institute of Nutrition, Mahidol University, Thailand based on standard procedures.

In order to preliminarily assess the storage stability of RUSF, sensory quality of RUSF was assessed after two weeks of storage under ambient conditions $\left(30.0^{\circ} \mathrm{C}, 58\right.$ percent relative humidity). Difference-from-control test was conducted by thirteen panelists from among staff of icddr,b and are caregivers familiar with feeding their children complementary food but not directly involved with the present study. Panelists received three samples (15-20 g in white plastic cups) for each formula, one stored at room temperature (test sample) and two controls (A and B) stored in a freezer. All samples were blinded to the panelist and were coded with three-digit random numbers except control sample A. They were randomly served to each panelist. Panelists were asked to rate for the degree of difference in odor and flavor of samples from the control sample A. The rating was performed on 5-point scale with 0 : no difference and 4: extremely different. No difference in odor and flavor was observed between sample that was kept at room temperature and the one kept in a freezer, suggesting that the RUSF could be kept at room temperature for up to two weeks without any change in its sensory quality. There was also no change in microbiological quality of RUSF stored at room temperature over two weeks. The product development stage took nine months between January-September 2011. However, the RUSF used for the acceptability trial were freshly prepared every alternative day.

\section{Acceptability trial}

\section{Outcome variables}

The primary outcome variable for the acceptability trial was to see the acceptability of RUSF or Pushti packet by measuring the amount of food consumed by children. The secondary outcome variable was to measure children's mothers' opinion on the food's color, flavor, mouth feel, and overall acceptability by using a seven point Hedonic Scale.

\section{Study settings}

The acceptability trial was carried out in an underprivileged community living in a slum in Mirpur, Dhaka,
Bangladesh. The slum in Mirpur was selected as the site of the study because it is inhabited by poor families, and represents a typical slum settlement in Bangladesh. Mirpur is one of the 27 Thanas of Dhaka City with a population of about one million in an area of 59 square kilometres. The acceptability study was conducted during January-February 2012. This was an open labeled study. Blinding was not done because the various types of foods were very distinct.

\section{Sample size}

The sample size was based to test the hypothesis that the mean consumption of RUSF during the acceptability test would be at least 40 percent of the amount offered. We assumed that the standard deviation of consumption would be 15 percent of the amount offered. The sample size of 30 for each diet would therefore allow us to reject the null hypothesis with 80 percent power if the true means were at least 60 percent. The sample size was also adjusted for multiple comparisons using Bonferonni correction.

\section{Enrollment}

All children in the community aged 6-18 months were screened for nutritional status and presence of any illness. Upon fulfilling the enrolment criteria (age 6-18 months, started semi-solid food) and receiving the consent for participation in the study from the parents or legal guardians, the children together with their respective mother/caregiver were randomly allocated into three different study groups and children were enrolled. Children did not meet the enrolment criteria if their weightfor-age or weight-for-height $\mathrm{z}$-score was $<-3$, if they had any acute illness or features suggestive of any chronic disease such as tuberculosis, any congenital anomalies such as trisomy 21 , cleft lip or palate.

\section{Randomization}

A total of 135 children from 6,152 households were identified (Figure 1) for randomization. Of these children, 90 children were assigned to three different study groups (rice-lentil RUSF, chickpea based RUSF or Pushti packet groups) using simple random sampling according to computer-generated random numbers. Computer generated numbers were given by another researcher within the same organization but not involved with the existing study.

\section{Intervention}

Pushti packet was offered at $50 \mathrm{~g}$. In order to maintain comparability, each RUSF was also offered at $50 \mathrm{~g}$ daily. However, the total energy obtained from Pushti packet was not equal to RUSF. The energy and nutrient content of the three foods i.e. rice-lentil-based RUSF, chickpeabased RUSF and Pushti packet is shown in Table 1. 


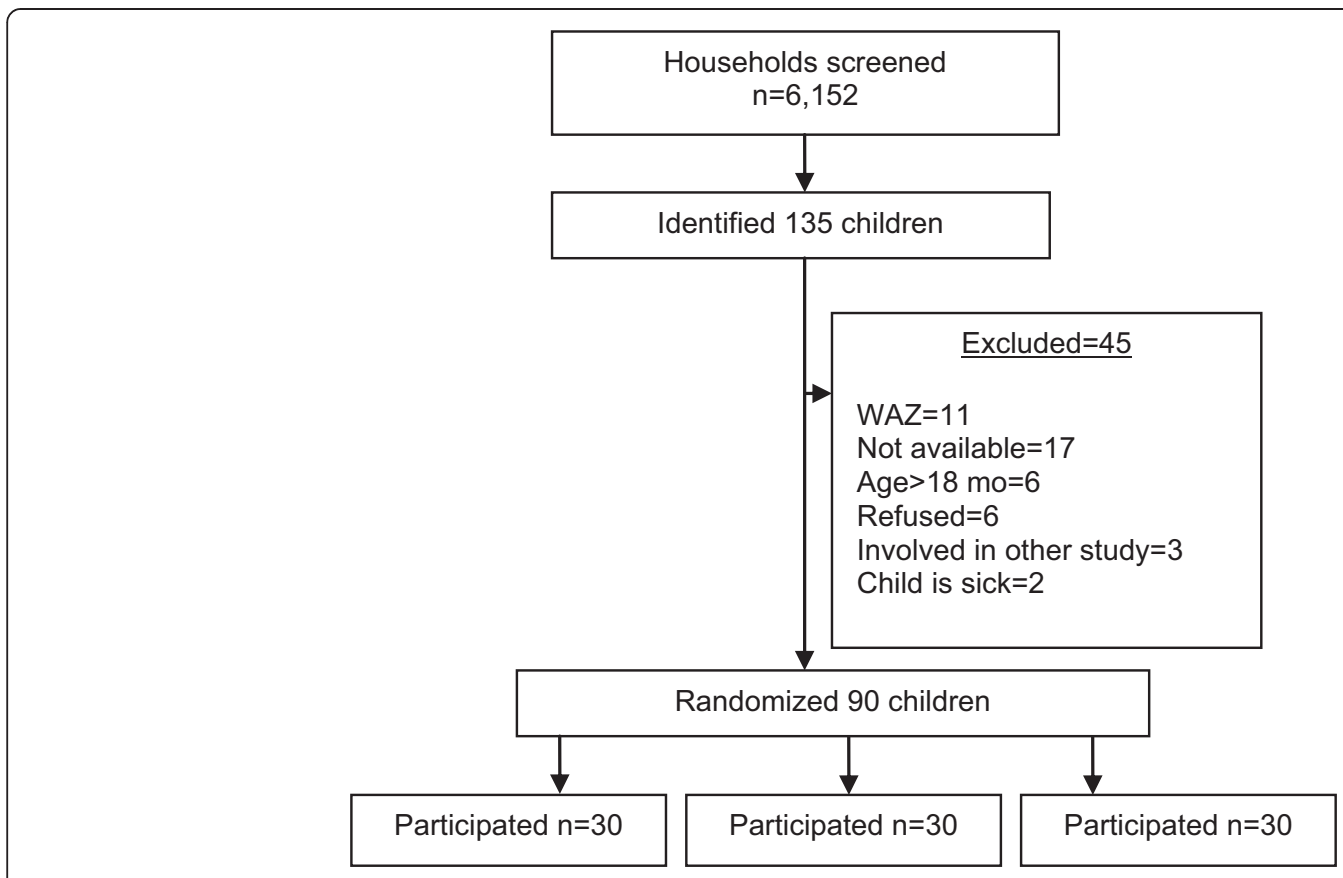

Figure $1 \mathrm{~A}$ trial profile.

Pushti packet was prepared using roasted rice powder $(26.3 \mathrm{~g})$, roasted lentil powder (13.2 g), molasses (6.6 g), and soybean oil $(3.9 \mathrm{~g})$ per serving. It does not contain any added micronutrients. Therefore, in addition to existing ingredients of Pushti packet, we gave one sachet of Pushtikona (Renata Limited, Dhaka), which is a micronutrient powder containing 15 micronutrients (vitamin A $0.40 \mathrm{mg}$, vitamin C $30 \mathrm{mg}$, vitamin D $0.005 \mathrm{mg}$, vitamin E $5 \mathrm{mg}$, Thiamine $0.5 \mathrm{mg}$, riboflavin $0.5 \mathrm{mg}$, niacin $6 \mathrm{mg}$, pyridoxine $0.5 \mathrm{mg}$, Cyanocobalamin $0.0009 \mathrm{mg}$, folic acid $0.15 \mathrm{mg}$, iron $10 \mathrm{mg}$, zinc $4.1 \mathrm{mg}$, copper $0.56 \mathrm{mg}$, selenium $0.017 \mathrm{mg}$, iodine $0.09 \mathrm{mg}$ ). While giving Pushti packet we allowed mothers to add water to the food mix as per requirement, and asked them to add the Pushtikona.

\section{Observation of feeds and interviews with caregivers}

The feeding on first day was held at the nutrition centre in Baoniabad slum of Mirpur, Dhaka. The first day feeding session enabled study staff to get familiarized with the mothers and children and also for the latter to be habituated to the food. After the first day feeding session all participants were supplied with the respective food supplement for two days to use under real life conditions with a daily dose of $50 \mathrm{~g}$. Before end of first two days supplementation, our field worker visited the households and continued her visit in the households every alternate day to give the supplements and recorded morbidity, if there was any. At the end of one week period, field workers requested the participants to come again to the nutrition centre and the feeding was observed for the second time. Data on this second day at the end of the one week period was included in the analysis.

The RUSF was prepared each morning by our health workers in icddr,b Food Processing Laboratory under supervision of the investigators, and then carried to the nutrition centre in Mirpur. On the first day of the study, information was sought on the families' wealth, standard of housing, family structure and parental characteristics. A trained research assistant recorded the children's nude weight or with light clothing using a digital scale with $10 \mathrm{~g}$ precision (Seca, model-345), length (using a calibrated length board), and mid upper-arm circumference to the nearest $\mathrm{mm}$ (using a non-stretch insertion tape). We ensured that infants were offered the assigned diet at least 2 hours after they were last fed.

During the feeding time, the mothers were asked to spoon feed their children the assigned diet until the child refused to eat. After a two-minute pause, the same food was offered a second time until s/he refused again. After a second two-minute pause, the food was offered a third time until refused again. After this third refusal, the feeding episode was considered terminated. The duration of the feeding (excluding the intervening 'pause periods') was recorded by stopwatch, and the total duration of the feeding was noted. The feeding episode took place under the direct supervision of a trained research assistant to make sure that feeding was not forceful. Children were considered as refusing intake if they moved their head away from 
Table 1 Composition of RUSF and Pushti Packet per $50 \mathrm{~g}$ (per serving)

\begin{tabular}{|c|c|c|c|}
\hline & $\begin{array}{l}\text { Rice-Lentil } \\
\text { based RUSF }\end{array}$ & $\begin{array}{l}\text { Chickpea } \\
\text { based RUSF }\end{array}$ & $\begin{array}{l}\text { Pushti } \\
\text { packet }\end{array}$ \\
\hline Energy (Kcal) & 264 & 267 & 188 \\
\hline Moisture (g) & 1.0 & 1.2 & ND \\
\hline Protein (g) & 5.1 & 6 & 4.9 \\
\hline Total fat (g) & 14.8 & 15.9 & 4.2 \\
\hline Carbohydrate (g) & 27.6 & 24.9 & 32.6 \\
\hline Dietary fibre (g) & 1.1 & 0.6 & ND \\
\hline Ash (g) & 1.95 & 2.5 & ND \\
\hline Vitamin A $(\mu \mathrm{g})$ & 427.5 & 294 & 0.39 \\
\hline B carotene $(\mu \mathrm{g})$ & 8.5 & 26.5 & ND \\
\hline Vitamin C (mg) & 16 & 20.5 & 0.65 \\
\hline Vitamin E (mg) & 10.41 & 14.0 & ND \\
\hline Vitamin $B_{1}(\mathrm{mg})$ & 0.475 & 0.78 & 0.07 \\
\hline Vitamin $B_{2}$ (mg) & 0.515 & 0.63 & 0.04 \\
\hline Calcium (mg) & 286.0 & 413.3 & 0 \\
\hline Phosphorus (mg) & 240 & 318 & ND \\
\hline Sodium (mg) & 20.5 & 37 & ND \\
\hline Potassium (mg) & 317 & 424.5 & ND \\
\hline Magnesium (mg) & 51.425 & 71.5 & ND \\
\hline Iron (mg) & 5.905 & 7.0 & 1.92 \\
\hline Copper (mg) & 0.34 & 0.4 & ND \\
\hline Zinc (mg) & 4.15 & 4.9 & 0.80 \\
\hline Chloride (mg) & 38.5 & 68.5 & ND \\
\hline Aflatoxin & Not detected & Not detected & ND \\
\hline Water activity $\left(24.6^{\circ} \mathrm{C}\right)$ & 0.32 & 0.32 & ND \\
\hline $\mathrm{pH}$ & 6.3 & 4.1 & ND \\
\hline Peroxide value & 0.2 & 0 & ND \\
\hline
\end{tabular}

ND: Not determined.

the food, cried, clamped the mouth shut or clenched the teeth, or became agitated, spit out the food or refused to swallow. The amount of food ingested was calculated by subtracting the left-over from the offered amount. Preweighed napkins were provided; any food that was regurgitated, vomited or spilled was swabbed, the napkin weighed and subtracted from the weight of the amount offered. Using a 7-point Hedonic Scale in which each point $(1=$ dislike extremely, $2=$ dislike moderately, $3=$ dislike $4=$ neither dislike nor like, $5=$ like slightly, $6=$ like moderately, $7=$ like extremely) was depicted by a facial drawing, we asked mothers to rate the food's color, flavor, mouth feel, and overall acceptability.

\section{Analysis}

We performed data analysis using SPSS version 16. Background characteristics of the participants were evaluated by using descriptive statistics. For the acceptability test, we calculated the percent of RUSF that children consumed as well as mean \pm SD of the amount of the RUSF. We used one-way ANOVA and post-hoc Bonferonni test to detect differences in continuous variables, and chisquared tests for proportions. Data from the Hedonic Scale questions were presented as mean \pm SD.

\section{Ethical approval}

Ethical approval was obtained from icddr,b Institutional Review Board. Informed and signed consent were obtained individually from the caregivers of the participants in the study, and all data were coded to remove identifying information and secure confidentiality. The trial was registered at Clinical trials.gov and the registration number of this trial is NCT01553877.

\section{Results}

\section{Development of RUSF}

Rice, lentil and chickpea were chosen as ingredients for making RUSF. These ingredients are widely grown and consumed in Bangladesh and other South Asian countries. Two varieties of RUSF were developed - one was rice and lentil based and the other was chickpea based. Dried skimmed milk powder, sugar, soybean oil and vitamin mineral premix were the common ingredients for both RUSF. The total energy content of $50 \mathrm{~g}$ of ricelentil and of chickpea-based RUSF was $264 \mathrm{kcal}$ and $267 \mathrm{kcal}$ respectively. Protein-energy ratio (PER) for rice-lentil and chickpea recipes were 7.7 and 8.9 percent respectively, whereas fat-energy ratio (FER) for the two recipes were 50.4 percent and 53.6 percent respectively. These RUSF had greater energy density than Pushti packet (energy $188 \mathrm{kcal}$ per $50 \mathrm{~g}$, PER 10.4 percent, and FER 20.1 percent). Preparation of RUSF undergoes different steps i.e. roasting, particle size reduction, homogeneous blending and packaging (Figure 2).

\section{Acceptability trial}

A total of 135 children were identified in the community of whom 90 children were found eligible; they were enrolled and completed the trial. They included 52 girls (57.8 percent) and 38 boys ( 42.2 percent), and their mean age was $13.9 \pm 2.9$ months. Mean years of household head's education was $6.0 \pm 3.8$ years (Table 2). Individual or household characteristics did not differ significantly by study groups (Table 2).

Children consumed on an average $23.1 \pm 15.4 \mathrm{~g}$ of offered food which took them 20.9 \pm 9.6 mins (Table 3). Amounts of food consumed by rice-lentil and chickpeabased food groups, and the times taken to consume them did not differ significantly. Children consumed an average of 47.1-56.7 percent of the RUSF and 34.4 percent of Pushti packet offered. There was a significant 


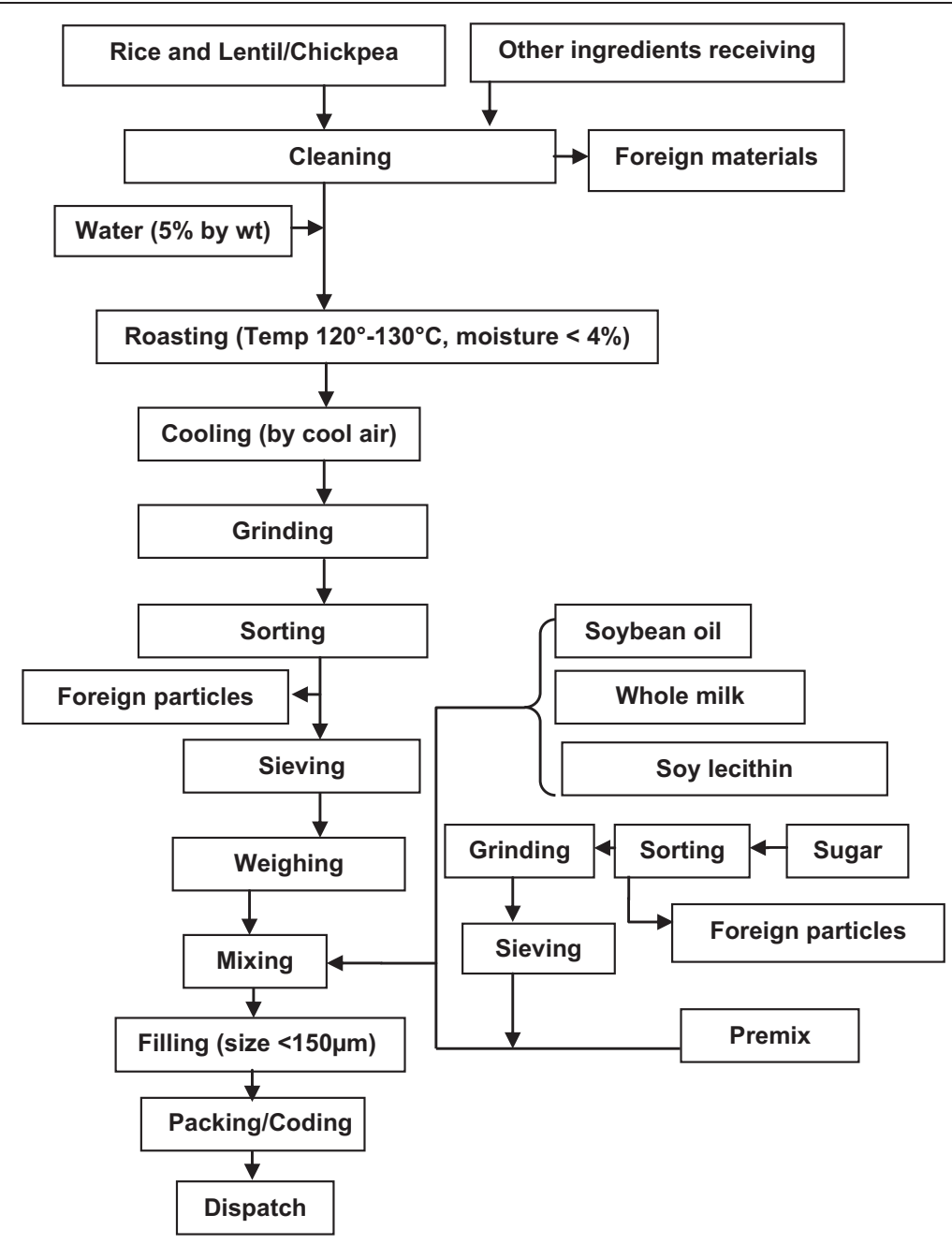

Figure 2 Flow diagram of RUSF production.

difference $(p=0.012)$ in amount of chickpea-based RUSF and Pushti packet consumed (the former was better) (Table 3). On the 7-point Hedonic Scale, mean response for each sensory quality (color, flavor, mouth feel, and overall liking by mother's opinion) of all foods was more than 6. Rice-lentil, and chickpea-based RUSF were significantly better compared to Pushti packet in terms of 'overall liking' (Table 3).

Interviews with the caregivers/mothers with the structured questionnaire revealed that $18 / 30$ children (60\%) liked rice-lentil and 20/30 children (66\%) preferred the chickpea-based RUSF. In Pushti packet group, only 12/ $30(40 \%)$ caregivers reported that their children liked the supplement. The common reason stated by the mother for her child's liking was that the child ate most of the portion served. Almost one third of the caregivers felt that the consistency of the RUSF was appropriate for children. Fifteen caregivers felt that the consistency of rice-lentil (5/30) and chickpea-based (10/30) supplements was thick. Some caregivers reported that ricelentil (10/30) and chickpea based (9/30) supplements were too sweet in taste, whereas Pushti packet study participants $(11 / 30)$ reported the taste was neither sweet nor salty. Few mothers (5/60) in rice-lentil and chickpea based RUSF study groups mentioned that the food had a strong taste which is more like a medicine.

\section{Discussion}

Our results suggest that rice-lentil and chickpea-based RUSF were more acceptable than Pushti packet, which was the least acceptable of the three foods studied. The assessment of the acceptability of the three food supplements was a bit challenging because we had to depend partially on the opinion of mothers whose tastes and food preferences, as adults, are different from those of the children. Although our primary objective was to 
Table 2 Characteristics of children who completed the study

\begin{tabular}{lccc}
\hline Characteristics & $\begin{array}{c}\text { Rice-Lentil } \\
\text { based RUSF } \\
(\mathbf{n}=\mathbf{3 0})\end{array}$ & $\begin{array}{c}\text { Chickpea } \\
\text { based RUSF } \\
(\mathbf{n = 3 0 )}\end{array}$ & $\begin{array}{c}\text { Pushti } \\
\text { packet } \\
(\mathbf{n}=\mathbf{3 0})\end{array}$ \\
\hline Child characteristics & $\mathbf{( 1 )}$ & $\mathbf{( 2 )}$ & $\mathbf{( 3 )}$ \\
\hline Age (mo), mean \pm SD & $14.1 \pm 2.9$ & $13.9 \pm 2.6$ & $13.8 \pm 3.2$ \\
Sex\% Girl (n) & $60(18)$ & $53.3(16)$ & $60(18)$ \\
Weight, Kg (mean \pm SD) & $8.2 \pm 0.6$ & $8.3 \pm 0.7$ & $8.1 \pm 0.7$ \\
Height, cm (mean \pm SD) & $72.7 \pm 3.5$ & $73.2 \pm 3.2$ & $71.5 \pm 4.4$ \\
MUAC, mm (mean \pm SD) & $139.1 \pm 7.2$ & $137.7 \pm 7.4$ & $136.6 \pm 6.8$ \\
Weight-for-height z & $16.7(5)$ & $3.3(1)$ & $6.7(2)$ \\
score <-2,\% (n) & & & \\
Height-for-age z score & $36.7(11)$ & $36.7(11)$ & $50.0(15)$ \\
$<-2, \%$ (n) & & & \\
Weight-for-age z score & $33.3(10)$ & $26.7(8)$ & $36.7(11)$ \\
$<-2, \%$ (n) & & & \\
Household characteristics & & & \\
Family size (mean \pm SD) & $4.43 \pm 1.3$ & $4.9 \pm 1.9$ & $4.6 \pm 2.0$ \\
Household head completed & $73.3(22)$ & $60.0(18)$ & $63.3(19)$ \\
primary education,\% (n) & & & \\
Using shared latrine,\% (n) & $80.0(24)$ & $86.3(26)$ & $80.0(24)$ \\
Tap water source of drinking & $96.7(29)$ & $96.7(29)$ & $93.3(28)$ \\
water,\% & & & \\
\hline
\end{tabular}

measure the mean proportion of offered food consumed by the children but we also measured the mean Hedonic Scale score. Our rationale was that with no forced feeding, the amount of the offered food consumed by children would depend largely on the extent to which they liked the food, given that none of the children were fed for at least 2 hours prior to the feeding session. Children consumed an average of 47.1-56.7 percent of the RUSF offered and 34.4 percent of Pushti packet offered. Mean Hedonic Scale score for Pushti packet was also significantly lower compared to the two RUSF. We can, therefore, say with reasonable certainty that children accepted rice-lentil and chickpea based RUSF more compared to Pushti packet. The Hedonic Scale responses from the mothers suggested a high level of acceptability, but as observed in a similar study in Mexico and Ghana [8,13], such Hedonic Scale responses may not be conclusive because respondents could be reluctant to give any negative comment [14]. Our mean Hedonic Scale across all three foods was high suggesting this may have also occurred in our study. On the other hand, total consumption of the offered food is an option to assess the acceptability of food supplements $[8,10]$. Thus, combining the results from Hedonic Scale testing and total consumption is probably the best way to judge the acceptability of the RUSF.

The concerns raised by few caregivers about the taste of RUSF being similar to a medicine warrants discussion. Our general observation was that caregivers considered the supplement as food, and therefore, they seem to expect it to taste much the same way as a typical food might taste. The relatively high mineral concentration makes any attempt to get the supplement to taste like a typical food a challenge, from a food technology perspective [3]. There may be a way to deal with the medicinal taste issue: it should be explained to caregivers that the RUSF, although it looks like food, has a high nutrient concentration and therefore may not taste like a normal

Table 3 Results of test feeding of RUSF

\begin{tabular}{|c|c|c|c|c|c|c|c|}
\hline & \multirow{2}{*}{$\begin{array}{l}\text { Rice-Lentil based } \\
\text { RUSF }(n=30) \\
(1)\end{array}$} & \multirow{2}{*}{$\begin{array}{l}\text { Chickpea based } \\
\text { RUSF }(n=30) \\
(2)\end{array}$} & \multirow{2}{*}{$\begin{array}{l}\text { Pushti packet } \\
(\mathrm{n}=30) \\
(3)\end{array}$} & \multirow[t]{2}{*}{$P$ value $^{1}$} & \multicolumn{3}{|c|}{$P$ value $^{2}$} \\
\hline & & & & & 1 vs.2 & 2 vs.3 & 1 vs.3 \\
\hline \multicolumn{8}{|l|}{ Mean Hedonic Scale (mean \pm SD) } \\
\hline Color of the supplement & $6.9 \pm 0.2$ & $6.9 \pm 0.3$ & $6.8 \pm 0.4$ & ns & - & - & - \\
\hline Aroma/flavor of the supplement & $6.8 \pm 0.4$ & $6.8 \pm 0.3$ & $6.5 \pm 0.6$ & 0.042 & ns & 0.049 & ns \\
\hline Texture/mouth feel & $6.7 \pm 0.4$ & $6.8 \pm 0.3$ & $6.2 \pm 0.7$ & 0.000 & ns & 0.000 & 0.002 \\
\hline Overall Liking & $6.9 \pm 0.2$ & $6.9 \pm 0.3$ & $6.4 \pm 0.6$ & 0.000 & ns & 0.000 & 0.000 \\
\hline Amount offered, g (mean \pm SD) & $50.4 \pm 0.5$ & $50.2 \pm 0.5$ & $49.9 \pm 1.2\left(118.0 \pm 12^{*}\right)$ & ns & - & - & - \\
\hline Amount consumed, g (mean \pm SD) & $23.8 \pm 14$ & $28.4 \pm 15$ & $17.1 \pm 14\left(40.8 \pm 35^{*}\right)$ & 0.015 & ns & 0.012 & ns \\
\hline $\begin{array}{l}\text { Percent of food consumed from offered } \\
\text { food }(\%)\end{array}$ & $47.2 \pm 28$ & $56.7 \pm 31$ & $34.4 \pm 28$ & 0.017 & ns & 0.014 & ns \\
\hline $\begin{array}{l}\text { Energy received from consumed food } \\
\text { (mean } \pm \text { SD), Kcal }\end{array}$ & $125 \pm 76$ & $152 \pm 83$ & $64 \pm 53$ & 0.000 & ns & 0.000 & 0.005 \\
\hline Feeding time, minutes (mean $\pm S D$ ) & $23.0 \pm 10$ & $20.7 \pm 10$ & $20.4 \pm 7$ & ns & - & - & - \\
\hline Velocity, $\mathrm{g} / \mathrm{min}$ & $1.3 \pm 1.0$ & $1.9 \pm 2.2$ & $0.8 \pm 0.8$ & 0.020 & ns & 0.016 & ns \\
\hline
\end{tabular}

ns: Not significant at $5 \%$ level; *after adding water; ${ }^{1} \mathrm{ANOVA} ;{ }^{2}$ post-hoc. 
food to few caregivers. Indeed it would be a point for counseling when the product will be launched at larger scale in a nutrition program.

Pushti packet was found less acceptable among children and caregivers. This supplement had one major characteristic that contributed to its lesser acceptance by the children or caregivers, which is: adding water to Pushti packet increases the volume of food and in turn it reduces the sweetness. Moreover, the fat content is less than RUSF. This study has provided useful insights for the efficacy trial of RUSF which is now being conducted in Gaibandah, in the northern part of Bangladesh, in collaboration with John Hopkins University and the World Food Programme. In this efficacy trial, approximately 5000 children, 6-18 months old, have been randomly assigned to the two locally produced RUSF, Supercereal Plus (also known as wheat soya blend plus plus or $\mathrm{WSB}++$ ) and a commercially available, imported food supplement called Pumpy'Doz ${ }^{\mathrm{Ta}}$. The trial will not only evaluate the effects of RUSF on the nutritional status of children, but will also provide extensive information on the long term acceptability of these products and add to what we have learned from this acceptability study.

\section{Conclusion}

We developed two RUSF based on locally available food ingredients. We conclude that the newly developed ricelentil and chickpea-based RUSF are acceptable to children and their caregivers. This study presenting acceptability data on locally produced RUSF for children, which is a novel way to ensure nutritional adequacy of children's diet particularly those living in food insecure conditions, and is nutritionally more complete than Pushti packet.

\section{Competing interests}

Authors do not have any conflict of interest in writing this paper.

\begin{abstract}
Authors' contribution
Conceptualized the work, participated in data collection and management, and drafting of manuscript: TA, NC, MIH, NT and MMI. Provided technical assistance and contributed to the manuscript: GS. Helped in interpretation of findings, and contributed to the critical revision of the manuscript for making the final draft for submission: SdP, GS, RF, SAS, MP, KPW, and PC. All authors approved the draft.
\end{abstract}

\section{Acknowledgments}

This research activity was funded by World Food Programme (WFP) through Project Laser Beam and a sub-agreement from John Hopkins University (JHU). icddr,b acknowledges with gratitude the commitment of WFP and $\mathrm{JHU}$ to its research efforts. icddr,b gratefully acknowledges the following donors which provide unrestricted support: Australian Agency for International Development (AusAID), Government of the People's Republic of Bangladesh, Canadian International Development Agency (CIDA), Swedish International Development Cooperation Agency (Sida), and the Department for International Development, UK (DFID).

\section{Author details}

${ }^{1}$ Centre for Nutrition and Food Security, icddr,b, 68 Shaheed Tajuddin Ahmed Sarani, Mohakhali, Dhaka 1212, Bangladesh. ${ }^{2}$ James P. Grant School of Public Health, BRAC University, Dhaka, Bangladesh. ${ }^{3}$ Food Science Unit, Institute of Nutrition, Mahidol University, Nakhon Pathom 73170, Thailand.
${ }^{4}$ World Food Programme, Via Cesare Giulio Viola 68/70, Rome 00148, Italy. ${ }^{5}$ DSM Nutritional Products Ltd, 4303 Kaiseraugst, Switzerland. ${ }^{6}$ World Food Programme, E/8A Rokeya Sharani, Agargaon, Sher-e-Bangla

NagarDhaka-1207, Bangladesh. ${ }^{7}$ Center for Human Nutrition, Department of International Health, Johns Hopkins Bloomberg School of Public Health, Baltimore, MD 21205, USA.

Received: 26 January 2014 Accepted: 19 June 2014

Published: 27 June 2014

\section{References}

1. NIPORT, Mitra and Associates, Macro International: Bangladesh Demographic and Health Survey 2011. Dhaka, Bangladesh and Calverton, Maryland, USA: NIPORT, Mitra and Associates, Macro International; 2011:18.

2. Ahmed T, Bhutta ZA, Goel KM: Nutrition: Protein-energy malnutrition and micronutrient deficiencies in childhood. In Hutchison's Pediatrics. Edited by Goel KM, Gupta DK. New Delhi: Jaypee Brothers; 2012.

3. Kimmons JE, Dewey KG, Haque E, Chakraborty J, Osendarp SJM, Brown KH: Low nutrient intakes among infants in rural Bangladesh are attributable to low intake and micronutrient density of complementary foods. J Nutr 2005, 135:444-51.

4. Arsenault JE, Yakes EA, Hossain MB, Islam MM, Ahmed T, Hotz C, Lewis B, Rahman AS, Jamil KM, Brown KH: The current high prevalence of dietary zinc inadequacy among children and women in rural Bangladesh could Be substantially ameliorated by zinc biofortification of rice. J Nutr 2010, 140:1683-90.

5. Yakes EA, Arsenault JE, Islam MM, Hossain MB, Ahmed T, German JB, Gillies LA, Rahman AS, Drake C, Jamil KM, Lewis BL, Brown KH: Intakes and breast-milk concentrations of essential fatty acids are low among Bangladeshi women with 24-48-month-old children. Br J Nutr 2011, 105:1660-1670.

6. Bhutta ZA, Ahmed T, Black RE, Cousens S, Dewey K, Giugliani E, Haider BA, Kirkwood B, Morris SS, Sachdev HP, Shekar M, Maternal and Child Undernutrition Study Group: What works? Interventions for maternal and child undernutrition and survival. Lancet 2008, 371:417-40.

7. Bhutta ZA, Das JK, Rizvi A, Gaffey MF, Walker N, Horton S, Webb P, Lartey A, Black RE, The Lancet Nutrition Intervention Review Group, and the Maternal and Child Nutrition Study Group: Evidence-based interventions for improvement of maternal and child nutrition: what can be done and at what cost? Lancet 2013, 282:452-477.

8. Adu-Afarwuah S, Lartey A, Zeilani M, Dewey KG: Acceptability of lipidbased nutrient supplements (LNS) among Ghanaian infants and pregnant or lactating women. Matern Child Nutr 2011, 7:344-56.

9. Bisimwa G, Owino VO, Bahwere P, Dramaix M, Donnen P, Dibari F, Collins S: Randomized controlled trial of the effectiveness of a soybean-maizesorghum-based ready-to-use complementary food paste on infant growth in South Kivu, Democratic Republic of Congo. Am J Clin Nutr 2012, 95:1157-64.

10. Phuka J, Ashorn U, Ashorn P, Zeilani M, Cheung YB, Dewey KG, Manary M, Maleta K: Acceptability of three novel lipid-based nutrient supplements among Malawian infants and their caregivers. Matern Child Nutr 2011, 7:368-77.

11. Smith VE: Linear programming models for the determination of palatable human diets. J Farm Econ 1959, 31:272-83.

12. Briend $A$, Ferguson $A E$, Darmon $N$ : Local food price analysis by linear programming: a new approach to assess the economic value of fortified food supplements. Food Nutr Bull 2001, 22:184-189.

13. Young SL, Blanco I, Hernandez-Cordero S, Pelto GH, Neufeld LM: Organoleptic properties, ease of use, and perceived health effects are determinants of acceptability of micronutrient supplements among poor Mexican women. J Nutr 2010, 140:605-11.

14. Albaum G: The Likert scale revisited: an alternate version. J Mark Res Soc 1997, 39:331-48.

doi:10.1186/1471-2431-14-164

Cite this article as: Ahmed et al:: Development and acceptability testing of ready-to-use supplementary food made from locally available food ingredients in Bangladesh. BMC Pediatrics 2014 14:164. 